Referencia para citar este artículo: Patiño-López, J. A. (2017). Prácticas familiares de paz: un acercamiento a las narrativas de jóvenes universitarios. Revista Latinoamericana de Ciencias Sociales, Niñez y Juventud, 15 (2), pp. 1207-1222. DOI:10.11600/1692715x.1522824022017

\title{
Prácticas familiares de paz: un acercamiento a las narrativas de jóvenes universitarios*
}

\author{
JHotna Alexandra Patiño-López ${ }^{* *}$ \\ Profesora Universidad de Caldas, Colombia.
}

Artículo recibido en febrero 24 de 2017; artículo aceptado en mayo 30 de 2017 (Eds.)

- Resumen (analítico): Objetivo: identificar la forma en que la familia como grupo socializador desarrolla potencialidades afectivas, comunicativas, éticas, y prácticas favorables para la construcción de paz cotidiana. Metodología: es un estudio cualitativo interpretativo, realizado mediante narrativas biográficas, analizadas en forma colaborativa con los agentes. Resultados: encontré que la construcción socio-familiar de significados en torno a la paz se asocia al contexto, a la experiencia de vida familiar y al reconocimiento de cinco prácticas familiares. Alcances: las prácticas familiares como compartir en familia, distribuir los trabajos domésticos, dialogar en familia, tomar decisiones de forma conjunta y cuidar en familia, aportan a la democratización de la vida familiar y a la construcción de paz a partir de las interacciones.

Palabras clave: joven universitario, familia, educación para la paz (Tesauro de Ciencias Sociales de la Unesco).

Palabras clave autora: narrativas, significados, prácticas familiares, construcción de paz.

\section{Family practices of peace: an approach in narratives of university students}

- Abstract (analytical): objective: to identify the way in which the family as a socializing group develops affective, communicative, ethical and favorable practices for the construction of daily peace. Methodology: it is a qualitative study interpretative, realized through biographical narratives, analyzed in a collaborative way with the agents. Results: it was found that the socio-familiar construction of meanings around peace is associated with the context, the family life experience and the recognition of five family practices. Scope: family practices such as family sharing, domestic work distribution, family dialogue, joint decision-making and family care contribute to the democratization of family life and the building of peace through interactions.

Key words: young university student, family, education for peace (Social Science Unesco Thesaurus). Key words author: narratives, meanings, family practices, peacebuilding.

Práticas familiares de paz: uma abordagem a partir de narrativas de estudantes universitários

- Resumo (analítico): objetivo: identificar como a família como um grupo de socialização desenvolve potencial emocionais, de comunicação, éticos e práticas favoráveis para a construção da paz todos os dias. A metodologia: é um estudo qualitativo interpretativa, conduzida por relatos

El presente artículo de investigación científica y tecnológica presenta los resultados de la investigación en el aula titulada "Prácticas de paz en la vida familiar: un acercamiento desde las narrativas de un grupo de estudiantes de Desarrollo Familiar y Trabajo Social de la Universidad de Caldas", realizada entre el 1 de julio de 2016 y el 7 de diciembre de 2016, financiada por la Vicerrectoría de Investigaciones y Posgrados de la Universidad de Caldas. Acta No 07 de 2016 Área: Ciencias Sociales. Subárea: Estudios de Familia.

** Profesional en Desarrollo Familiar de la Universidad de Caldas. Magíster en Educación y Desarrollo Humano del Cinde-Universidad Manizales. Profesora del Departamento de Estudios de Familia de la Universidad de Caldas. Coordinadora del GT Familias, géneros y diversidades. Investigadora Asociada Colciencias. Orcid: 0000-0002-8431-7317. Índice H5: 9. Correo electrónico: Johanna.patino@ucaldas.edu.co

Rev.latinoam.cienc.soc.niñez juv 15 (2): 1207-1222, 2017 
biográficos analisados em colaboração com os agentes. Resultados: verificou-se que os significados de construção sócio-familiares sobre a paz está associada ao contexto, a experiência da vida familiar eo reconhecimento de cinco práticas familiares. Ambito: práticas familiares como a partilha de família, distribuir o trabalho doméstico, o diálogo familiar, tomar decisões em conjunto e família carinhosa ajudar para a democratização da vida familiar e à construção da paz a partir das interações.

Palavras-chave: faculdade jovem, família, educação para a paz (Thesaurus de Ciências Sociais da Unesco).

Palavras-chave autora: narrativas, significados, práticas familiares, construção da paz.

\section{-1. Introducción. -2. Puntos de partida contextuales y teóricos. -3. Metodología. -4. Hallazgos. -5 . Conclusiones. -Lista de referencias.}

\section{Introducción}

En la investigación que da origen a este artículo, reconozco la actual transición social y política que vive el país a raíz de los procesos de acuerdos de paz con grupos guerrilleros, y de la posibilidad y la responsabilidad compartida que representa participar en tales nuevos acuerdos para construir la democracia.

Esto invita a considerar los actores, los escenarios y las condiciones que usualmente no se han tenido en cuenta de forma explícita en las comprensiones asociadas a la construcción de paz, porque ésta ha sido ligada especialmente a los ámbitos propios de la democracia liberal. En este sentido, la inquietud por el lugar y el aporte potencial de las Familias como agentes con prácticas socializadoras concretas, adquiere un especial interés y relevancia.

La intención política de la investigación fue vindicar la experiencia familiar de los individuos jóvenes universitarios como un espacio de creación cotidiana de condiciones y prácticas de paz.

Con esta intención de fondo, los objetivos que tracé para la investigación fueron: a) interpretar las prácticas familiares de construcción de paz que reconocen los estudiantes del programa de desarrollo familiar en sus narrativas autobiográficas, y b) generar un proceso práctico de reconocimiento, apropiación y motivación investigativa con el grupo de estudiantes adscritos al curso de investigación cualitativa ofertado por el departamento de estudios de familia de la Universidad de Caldas, en el segundo semestre del año 2016.

\section{Puntos de partida contextuales y teóricos}

\section{El lenguaje y la narración}

De acuerdo con la filosofía del lenguaje, con el constructivismo cultural y con el construccionismo social, es posible concebir el lenguaje como una fuente de elementos significativos para la construcción de paz en la vida familiar.

Según los postulados de la ontología del lenguaje y del construccionismo social planteados por Echeverría (2003) y por Gergen (2007), aunque hay condicionamientos de orden biológico, histórico y social externos al sujeto, las personas nacen dotadas de la posibilidad de participar activamente en el diseño de su propia forma de ser. Esto significa que la persona no está determinada a ser de una única y permanente forma. Por el contrario, es un proyecto en construcción, mediado por la capacidad generativa del lenguaje en contextos históricos y culturales. De modo que lo que hace ser como son a los seres humanos, es el lenguaje. Según Echeverría (2003):

El lenguaje, es un sistema de coordinación de la coordinación del comportamiento y está presente en nuestras acciones $\mathrm{y}$, como tal, está enclavado en sus prácticas sociales, en la forma en que sus miembros interactúan entre ellos. Un sistema de lenguaje no es un espacio uniforme. Al contrario, es una estructura de interacción diversificada en la que cada miembro de la comunidad desempeña un papel diferente. El sistema de lenguaje es una estructura 
de relaciones, y la posición de cada miembro de la comunidad dentro de esta estructura es un aspecto importante... en el proceso de individualización, en la constitución de los individuos como individuos. Somos lo que somos a partir de las relaciones que establecemos con los demás (p. 227).

El lenguaje es, pues, una construcción social de las interacciones mediadas por el contexto y por las estructuras biológicas. Por eso, Echeverría (2003) piensa que el lenguaje nace de la interacción social entre los seres humanos, de modo que es un fenómeno social, aunque es claro que se requieren estructuras biológicas y materiales para que se dé; su desarrollo no depende de ellas sino de las interacciones:

La principal posibilidad del lenguaje es la de ser un dominio consensual. La consensualidad significa que los participantes de una interacción social comparten el mismo sistema de signos (gestos, sonidos, etcétera) para designar objetos, acciones o acontecimientos en orden a coordinar sus acciones comunes. Sin dominio consensual no hay lenguaje, por tanto, el lenguaje deja de ser un asunto individual. El lenguaje permite al ser humano conferir sentido a su vida y reconocer la existencia de otros dominios existenciales no lingüísticos (...) incluso cuando apuntamos a los dominios del cuerpo la emocionalidad (los dos dominios primarios no lingüísticos) no podemos sino hacerlo desde el lenguaje como forma de conferir sentido, ya que toda forma de comprensión o de entendimiento pertenece al dominio del lenguaje. No hay un lugar fuera del lenguaje, desde el cual podamos observar nuestra existencia. Es precisamente a través del mecanismo de la «reconstrucción lingüística» como logramos acceso a los fenómenos no lingüísticos (Echeverría, 2003, p. 32).

De aquí se desprende una idea fecunda, expresada por varios autores y autoras que encuentran que el lenguaje permite hablar sobre las cosas, por supuesto, pero también hace que sucedan cosas. En la historia, los acontecimientos no ocurren por una misteriosa fuerza supra-histórica, pues la sociedad altera el curso espontáneo de los acontecimientos y hace que las cosas ocurran, lo que implica que la participación en el proceso continuo del devenir sea mediada por el lenguaje (Echeverría, 2003; Gergen, 2007; Bruner, 1989).

Ahora bien, las personas y los grupos no solo son construcción lingüística, sino también construcción social. Por ello el lenguaje va más allá de la oralidad, es todo aquello a través de lo cual el ser humano comunica y produce significados que le permiten coordinar acciones en contextos específicos; es decir, el lenguaje es toda forma de acción a partir de la cual el ser humano puede ser y hacer, estar y decidir, comunicar e interpretar (Bruner, 1989). Por tanto, el lenguaje es poder (Echeverría, 2003). Esto significa que el lenguaje no es ingenuo. Toda proposición, toda interpretación, abre y cierra posibilidades, habilita o inhibe cursos de acción, lo cual ocurre por el poder de las interpretaciones que se construyen en las narraciones.

Respecto a la narración, en un texto de 2012 sostuve que la narrativa es un tipo de construcción social permanente a partir de la cual el ser humano se construye y construye la realidad en la que vive. La narrativa es una forma de ser, de estar y de hacer en el mundo, por medio de la cual los sujetos y los grupos pueden expandir su capacidad reflexiva sobre las experiencias situadas; es decir, sobre la vida que han vivido en comunidades de sentido. Esto permite que al narrar reflexivamente los asuntos de la vida familiar, se logre desnaturalizarlos y dotarlos de nuevos sentidos y posibilidades de acción (Patiño-López, 2012).

Gergen (2007) expresa que la narrativa alberga una serie de posibilidades de comprensión que no buscan:

...comprobar visiones de conjunto o modelos explicativos generales, sino que busca reconocer y comprender relatos o historias singulares que permitan identificar elementos decisivos en las vidas de los agentes. De modo tal que se pueda identificar los rasgos trasversales o comunes entre distintos participantes, 
pero también rescatar las diferencias, lo genuino de cada biografía, de modo tal que en una misma narrativa se puedan hacer visibles y audibles en un mismo nivel de legitimidad las narraciones convergentes y divergentes, o la polifonía de voces que reflejan la dimensión problemática del conocimiento (p. 165).

\section{Metodología}

Las categorías centrales que orientaron la investigación fueron: prácticas familiares y significados de paz. La investigación se inscribió en una tradición cualitativa de reconstrucción narrativa (Creswell, 1998).

De acuerdo con Freeman, Epston y Lobovits (2001), las narraciones no se limitan a describir, sino que tienen la capacidad de configurar la vida de las personas porque son acciones que generan otras acciones; por virtud de las narraciones se llega a conocer las maneras en que los individuos jóvenes estudiantes y sus familias significan asuntos como las prácticas de paz en la vida familiar, y cómo éstas hacen parte de la constitución activa de las subjetividades e intersubjetividades que se evidencian en asuntos como la transformación de conflictos y la distribución del poder en la familia.

Como técnicas de la investigación trabajé la autobiografía y las entrevistas para obtener las narrativas que me permitieron conocer la interpretación que los estudiantes hacen de sus propias prácticas familiares para la construcción de paz. Según Maganto (2010), la autobiografía se ha considerado como forma de trabajo con las familias y con otros grupos sociales, porque en ella se expone la percepción de la realidad psicológica y social de las personas. Las autobiografías, las conversaciones en grupo y las observaciones en eventos sobre construcción de paz, suscitaron narrativas de los estudiantes que provocaron conversaciones intencionadas con integrantes de sus familias, amigos, amigas y colegas, en torno a los significados de paz y a los retos y posibilidades que actualmente enfrenta el país sobre este asunto.

Llevé a cabo la investigación en las siguientes fases:
- Aproximación conceptual a los fundamentos de la investigación. Realicé tres talleres en los cuales los estudiantes leyeron y discutieron documentos sobre investigación cualitativa como marco de referencia para el desarrollo del proyecto.

- Elaboración de narrativas mediante autobiografías, observaciones y conversaciones públicas. Cada estudiante entrevistó a una persona de su familia (30 entrevistas en total) y aplicó una guía de observación en los puestos de votación del plebiscito por el acuerdo con las Farc. Realicé dos actividades públicas en la universidad, sobre la paz en la vida familiar.

- Ordenamiento de las narrativas. Los estudiantes organizaron las narrativas en subgrupos de trabajo, para identificar elementos de significado.

- Preparación y exposición pública de resultados. Finalmente, los estudiantes y la profesora diseñaron una exposición fotográfica y un folleto para socializar los resultados de la investigación en la comunidad universitaria.

\section{Hallazgos}

\section{Tensiones en las narrativas}

El primer hallazgo se refiere a la identificación de una tensión narrativa que deja ver la existencia de distintos tipos de conocimiento y acción frente a la paz y la familia. Estos no son opuestos y contradictorios, sino hegemónicos e insurrectos, lo que quiere decir que coexisten en la experiencia familiar de la persona joven. Esta tensión la abordé según la literatura sobre la guerra en Colombia, en la que se expresan las posiciones hegemónicas y se contrastan con las narrativas de los estudiantes.

\section{Narrativas hegemónicas sobre la guerra en Colombia}

La historia colombiana contada a través de textos oficiales ha estado marcada por ciertos modos particulares de comprender los hechos económicos, culturales y políticos en los cuales se ha fundado una saga de sucesivas guerras. En el siglo XX se gestaron diferentes desencuentros entre las clases políticas, dirigentes y grupos 
disidentes, por el control político, económico, social y cultural de los territorios.

Según el Centro Nacional de Memoria Histórica (2013), es posible clasificar los periodos de la guerra reciente en cuatro momentos: El primero, entre 1958 y 1982 , marca la transición de la violencia bipartidista a la subversiva. El segundo es territorial y de crecimiento militar de las guerrillas y de los grupos paramilitares, de agudización de la crisis parcial del Estado, de irrupción del narcotráfico, de la Constitución Política de 1991 y sus posteriores efectos en los procesos de paz. Un tercer momento, entre 1996 y 2005 , marca el recrudecimiento del conflicto armado entre el Estado y los grupos insurrectos. El cuarto, entre 2005 y 2011, se caracteriza por una ofensiva militar del Estado que logró debilitar a la guerrilla.

La prolongación de la Guerra ha sido posible por las condiciones materiales de desigualdad y exclusión en el proyecto político, y por el proyecto discursivo hegemónico en todas las relaciones sociales. Este proyecto empezó con el surgimiento en 1962 de la "violentología", a raíz de la publicación del libro "La violencia en Colombia", resultado delaprimera investigación sobre los hechos de violencia acaecidos entre 1946 y 1958. El objetivo fue explicar las causas y las consecuencias de la guerra, como lo que expresa Bouthoul (1951) en relación con que la violencia es una condición propia de la especie humana que se desarrolla de acuerdo con el contexto. Esta primera perspectiva ha servido para relacionar de manera causal la violencia con la pobreza y el subdesarrollo.

La segunda perspectiva considera la guerra como un fenómeno social complejo que incluye aspectos económicos, demográficos, etnológicos, psicológicos y políticos, que no son aislados. Así, la guerra es una expresión de la violencia asociada a la necesidad de poder y de control.

La tercera perspectiva sostiene que la guerra es un instrumento asociado a la expresión de soberanía de los Estados y que cumple funciones sociales, políticas y económicas, de progreso y regulación.

Según Foucault (1980), estos argumentos originaron un tipo de conocimiento/poder construido por la academia y por el Estado y sus políticas, que puso como centro de sus interpretaciones la violencia como condición natural de las interacciones humanas y la guerra como destino inevitable, asociado a una idea lineal de la historia y a un enfoque progresivo y acumulativo del desarrollo. Estos argumentos sirvieron para crear una narrativa dominante sobre la violencia, que se instaló en las prácticas cotidianas. De acuerdo con Páramo (2008), la subjetividad es la concepción que tenemos sobre nosotros como personas. Estos sentidos no surgen de la individualidad, pues la identidad y la subjetividad se construyen socialmente a partir de elementos culturales como el lenguaje, las disciplinas científicas y los discursos ideológicos (Alvarado, Ospina, Quintero, Luna, Ospina \& Patiño-López, 2012).

Según Bruner (2004), no hay una subjetividad independiente de la existencia histórica cultural que se comparte con otros. Sobre esto, Gergen (2007) plantea que la persona y sus múltiples identidades y subjetividades se construyen y se controlan en las interacciones mediadas por el lenguaje, y cobran sentido en una cultura específica. Al respecto, Foucault (1980) considera que la forma como se nombra el mundo instala verdades que producen cuerpos y mentes dóciles para participar en la proliferación de conocimientos "globales", derivados de las acciones eruditas sobre la realidad producida por las ciencias, los medios de comunicación y las religiones, para asignar modos de ser, hacer, estar y decidir.

Para White (1987), el discurso es un aparato para la producción de significado ( $p$. $60)$, pero también de poder, pues el discurso que narra acontecimientos es acción que construye realidades que pueden revelar y ocultar aspectos de éstas. Al respecto, Fairclough (2008) encuentra que en lo narrado se asumen posiciones que aceptan o critican determinadas relaciones mediante la producción del discurso. Esta idea se refleja en varios relatos de los jóvenes participantes de la investigación:

"Mis papás me cuentan que siempre ha sido así, violencia y más violencia y por eso yo ya no me aterro de nada" (ab.1). 
"Mi abuelo me cuenta mucho sobre la violencia de los 50, a él le tocó salir volado de su finca y hoy en día él dice que todo sigue igual, y yo creo que sí es asi" (ab.5).

En Colombia se han puesto en marcha dispositivos discursivos de poder-saber-verdad que han producido conocimientos y narraciones hegemónicas sobre las interacciones sociales, fundadas y justificadas por la violencia que produce desplazamiento o aplazamiento conceptual y práctico. La paz se liga al fin de la guerra, y se ha pensado como una responsabilidad del Estado atada a normas que regulen la convivencia y garanticen la paz; de ahí que las narraciones sobre paz familiar se centren en la guerra, pues de esta forma se naturaliza la violencia. Los relatos de los jóvenes así lo expresan: “... profe, este país es así. Para qué jodernos" (cp.1); "en Colombia nos merecemos esta vida tan violenta" (cp.3).

En un contexto de guerra, la violencia se internaliza como parte natural de la vida, se acepta, se normaliza y se recrea en narrativas que justifican su existencia y la perpetúan mediante los juegos de los niños, a través de los medios de comunicación, de la vida laboral, de las pautas de la vida familiar y de la pareja, las creencias y los rituales:

"Como era niño, yo jugaba mucho a las pistolas"; "en mi caso me parece terrible ver noticias. ¡Qué pereza! solo muestran muerte y odio" (ab.12).

Las consecuencias de la naturalización se expresan en las comprensiones sobre la vida colectiva, como muestran los relatos de algunos jóvenes:

"Todos los colombianos heredamos la violencia y la llevamos en las venas"; "qué más podemos pedir, somos violentos por naturaleza”; "es imposible pensar en una Colombia sin guerra, si asi hemos vivido siempre, eso es lo que nos han enseñado"; yo no creo que lleguemos a la paz, en este país todos somos violentos"; "me parece una bobada votar pólvora en Gallinazos, así somos, violentos, asi nos quedamos porque este país no quiere cambiar" (ab.6).
La violencia crea una imagen fija de la realidad, totaliza la experiencia, impide que la persona se transforme y provoca narracionesacciones en favor de los dispositivos de control, de miedo y de muerte, para sostener el sistema de violencias:

"Uno termina acostumbrándose y ya lo que ve en las noticias no le parece raro, es como si uno al fin de cuentas aceptara que las cosas son asi y que uno no puede hacer nada por más que quiera" (cp.2).

En este sentido, la naturalización se expresa en narrativas que regulan las emociones y crean representaciones. Lechner (1997) argumenta que la instauración del miedo es una forma de erosión del nosotros, pues el miedo ha sido usado en la política para crear formas de actuación que dividen sus posibilidades de transformación, mediante narrativas hegemónicas: "(...) el miedo al otro como potencial agresor, el miedo a la exclusión económica y social y el miedo al sin sentido" (p. 181). Esto se observa en los relatos de los participantes:

"Creo que somos todos muy prevenidos, yo voy por la calle y a toda hora pienso que me van a atracar o me va a pasar algo, y así puede ser imposible llegar a la paz" (cp.1); "entre nosotros no hay mucho compartir, cada quien en su lugar y en sus cosas porque tenemos muchos miedos de tanta violencia que nos ha tocado... todos sabemos que es mejor vivir bien, en paz, y que debemos hacer algo, pero al final uno no hace nada es porque le da miedo que termine metido en un problema o que los demás lo excluyan a uno porque se mete en lo que no le importa... pareciera que hablar de paz es un problema” (cp.2).

\section{Conocimientos insurrectos y narrativas de jóvenes universitarios frente a la construcción de paz en la familia}

Las personas jóvenes tienen conocimientos expresados en narrativas alternativas frente a la paz y al lugar de las familias en su construcción. Este hallazgo fue posible comprenderlo a la luz de los planteamientos del construccionismo 
social, en donde se asume que el conocimiento y lo social no tienen características estables; son productos temporales, parciales y situados. En las interacciones humanas hay regularidades y hay emergencias. Según FriedSchnitman (2015), las posibilidades emergentes son estructuras de comprensión humana imaginativas, que influyen en la construcción de las significaciones.

Estas posibilidades se originan en los diálogos de comunidades discursivas:

"Para mí ha sido increible entender desde mi experiencia que mi familia es pacifica; yo siempre pensé que por vivir en un barrio tan violento nosotros también éramos asi" (ab7).

Lo emergente proviene del énfasis en la creatividad como capacidad para fijarnos en la pluralidad de discursos y de voces, de la posibilidad de coordinar acciones, y de la insurrección que interpela los mandatos sociales culturalmente impuestos por los sistemas hegemónicos de conocimiento. Según Guattari (1996), los dogmatismos limitan la creatividad y producen líneas de fuga que favorecen las contradicciones que se manifiestan -en palabras de Castoriadis (2007)- en lo instituido, es decir, en lo ausente de la regulación y la naturalización. El siguiente relato es una ilustración de esto:

"A mí me marcó mucho que, cuando estudiaba en el colegio, tenía una profesora de historia que nos hablaba de las guerra de Colombia y siempre acababa la clase diciendo, que este país era el infierno donde por desgracia nos había tocado vivir. Pero ahora, al escribir sobre mis prácticas familiares que generan paz, pude ver las cosas de otra forma. Ya no creo que sólo tengamos guerra, más bien, entiendo que sólo hemos hablado de la guerra y que no hemos buscado la paz en otras partes porque todo el tiempo hemos creído que la paz está lejos, entre los ejércitos Profe, como si la paz no fuera un asunto nuestro" (ab.7).

La perspectiva generativa es una forma de comprender la vida que expresa la posibilidad de mantener abiertos los procesos y las interacciones que, de acuerdo con Fried-
Schnitman (2015), expanden los espacios de lo dado, de lo trabajado o estudiado, de lo comprendido como definido, mediante la creación de significados y relaciones antes no consideradas por los sujetos y los grupos, que rompen con las determinaciones impuestas por los sistemas de saber-poder-verdad dominantes.

"Pues, aunque al inicio me pareció muy raro el ejercicio, a medida que fuimos avanzando me di cuenta que me servía mucho para ver a mi familia de otra forma. Yo siempre he creído que mis padres y mis hermanos son violentos porque gritan y pelean mucho, pero no me había dado cuenta de que yo también lo hago; pero además no había caído en la cuenta de que eso no es siempre, que también compartimos en familia" (ab.15).

Según Durán, Medina, González y Rolón (2007), los relatos de las personas dan forma a la percepción sobre las historias de vida, a los recuerdos seleccionados y evadidos. Permiten aproximarse a los mundos internos para comprenderlos. No obstante, la narrativa no contiene toda la vida de la persona; por eso, Gergen (2007) dice que es posible entender que en las historias de vida se desconocen sus posibilidades.

White y Epston (1993) piensan que en la narrativa se pueden resignificar las experiencias al tejer la memoria del pasado y la proyección del futuro, ya que "con cada nueva versión contada, las personas reescriben sus vidas" (p. 30). Así mismo lo interpreta Patiño-López (2017), al manifestar que las narrativas son formas de creación de la vida familiar con elementos y hechos que antes no habían sido considerados por ellos mismos y, por tanto, movilizan la reinterpretación de significados y la modificación de prácticas que originan nuevas configuraciones de sentido:

“(...) al principio, profe, me costó mucho porque no me gusta escribir, pero luego fue muy chévere porque era como si estuviera viendo a mi familia desde otro lugar. Por ejemplo, yo escribi sobre las fiestas de navidad, los cumpleaños, el día de la madre y también sobre los paseos, porque siempre los hemos 
hecho, pero nunca los había valorado como algo importante que nos ayudaba a vivir mejor, a vivir en paz" (cp.2).

La narrativa permite comprender cómo construir paz en la vida familiar según lo narrado, y según la percepción personal y colectiva de la vida, para interpretar en el relato las experiencias insurrectas que no han sido observadas en las comprensiones y en las acciones que orientan la vida. Esto es posible comprenderlo en el siguiente relato:

"La verdad es que nunca se me había ocurrido que la familia aportara a la paz, pero ya cuando uno lo piensa bien, ve que sí es asi porque uno crece en una familia donde le enseñan muchas cosas que más adelante uno usa y enseña a otros" (cp.5).

Foucault (1980) propone que hay, además de los conocimientos "globales o totales", una segunda clase de conocimientos socialmente construidos: los subyugados. Éstos son los que se gestan y se usan en las relaciones cotidianas locales, son los conocimientos cercanos que se reconocen porque se encuentran en circulación constante en las interacciones íntimas y públicas, y muestran rupturas o reinterpretaciones de los conocimientos globales. Se trata de conocimientos disruptivos ligados a las emociones, a las necesidades, al cuerpo, que sobreviven en los sistemas hegemónicos de saber/poder y que se consideran de bajo rango e insuficientes para ordenar la vida porque no pertenecen a la producción de conocimientos formales (White \& Epston, 1993). Esto se puede notar cuando los sujetos jóvenes manifiestan que:

“(...) es muy importante ver que el diálogo, la distribución del trabajo doméstico, el compartir y otras cosas más son acciones que hacemos todos los días y que aportan a la paz desde la vida cotidiana" (cp.2).

Aunque acepto que la construcción biográfica de estos individuos jóvenes se hizo en un contexto sociocultural marcado pornarrativas dominantes sobre la violencia y la guerra, en la reconstrucción de sus narrativas encontré que hay conocimientos insurrectos sobre la paz y la familia derivados de sus experiencias y de su historia familiar, que propician comprensiones y acciones generativas, y ayudan a construir conocimientos para replantear el lugar que tradicionalmente se le ha otorgado a la familia en la formación ciudadana y en la construcción de paz:

"Antes de estar en esta clase, antes de hacer esto, yo no sabía, no me había imaginado que uno desde la familia, desde su casa, desde sus relaciones puede crear paz" (cp.1).

Las narrativas generativas que muestran conocimientos insurrectos frente a la paz permiten que quienes hayan sido ocultados y dejados por fuera del proceso de construcción colectiva de conocimientos, acuerdos, sentidos, se manifiesten:

"En mis relatos me di cuenta de que la paz no se hace afuera sino adentro de uno y de sus redes, de su familia. $Y$ esto me cuestionó porque con el debate del acuerdo, del plebiscito y todo eso, yo había creído que eso era algo ajeno a mí. Ahora veo que no es así. Ya reconozco que todo lo que se hace en una familia para cuidar a los otros es parte de la posibilidad de vivir una sociedad diferente" (ob.1).

\section{Los significados de paz en las narrativas autobiográficas}

El segundo hallazgo alude a la relación entre el significado que los jóvenes y las jóvenes han construido de paz y sus contextos de procedencia y socialización. La interpretación del significado se realiza en interacciones con otros y con el contexto social y cultural. Las interacciones permiten construir y coordinar acciones mediante el lenguaje, aunque varían con el tiempo de las relaciones. Las interacciones inciden en los aprendizajes que permiten el desempeño social de las personas y la construcción de su subjetividad.

Según Muñoz (2008), la paz puede ser entendida como un símbolo de interpretación $\mathrm{y}$ acción, donde se involucran emociones $\mathrm{y}$ conocimientos. Sus raíces podrían hallarse en aspectos de carácter sicogenético, sociogenético, filogenético y ontogénico. En 
el proceso de interpretación, destaco que en las narrativas y en las entrevistas coexisten distintos significados de paz relacionados y construidos a partir de las dimensiones cognitivas, afectivas, comunicativas y éticas, y desde las experiencias particulares de socialización, procedencia, género y generación:

"Paz es respeto por lo diferente, es dar afecto y comprensión, ayudar a los demás, es ser más humano" (ab.19).

"Creo que la paz es un estado de la vida que se hace posible cuando las personas renunciamos a la violencia como forma de control" (ab.28).

"La paz es cuidar, es aprender a querer, es dar" (cp.1).

"La paz es una posibilidad que tenemos, es estar mejor con uno y con los demás siguiendo las normas" (cp.2).

En los estudiantes participantes identifiqué diferencias en el significado atribuido a la paz, según la procedencia rural o urbana, pero no así respecto a la condición de género. Para quienes proceden del sector rural, el significado de paz está ligado a un estado particular de las relaciones entre las personas, el entorno natural y otras especies. Este significado se refiere a un tipo de interacción que no está mediada por prácticas de violencia, control o destrucción, sino por vínculos afectivos de reconocimiento, cuidado, solidaridad, corresponsabilidad y creación. Para estos sujetos jóvenes, el significado de paz se adquiere en la educación que se realiza en las iglesias, en las escuelas y en las casas. Y permite encontrar condiciones para articular el pensar, el sentir y el actuar, según las normas en los espacios de la vida en común.

Destaco significados que señalan la paz como una condición que se experimenta interna y externamente, y que depende de las circunstancias que el medio social ofrece. Estos individuos jóvenes asocian la construcción de paz con las formas de acción que permiten garantizar los derechos por parte del Estado. Puedo señalar que para estas personas jóvenes, la paz implica ausencia de conflictos bélicos y de grupos armados.

Para los estudiantes procedentes de sectores urbanos, el significado de paz está vinculado a la construcción social de formas de relaciones mediadas por el diálogo y por el respeto a las diferencias de pensamiento y acción. Sostienen que estos significados se construyen en las interacciones cotidianas en la familia, en el barrio, en la escuela, en el grupo de pares y en los medios de comunicación. En estas interpretaciones, es posible identificar que para estos individuos jóvenes la construcción de paz implica reflexión, autonomía, capacidad de elegir formas de vida y de relacionarse de manera horizontal para crear acuerdos $y$ cambios.

Destaco los elementos que resaltan el significado de paz:

En primer lugar, para todos los jóvenes y las jóvenes participantes, la paz significa formas alternativas de transformación de conflictos en todas las dimensiones y relaciones. Estas formas alternativas se caracterizan por el uso de la palabra, el argumento, el afecto y el reconocimiento, como mediadores de las diferencias y potenciadores de capacidades.

En segundo lugar, aparece la justicia y la equidad social como elementos centrales de la construcción de condiciones que permitan a todas las personas ejercer sus derechos. Este aspecto permite ver que, para estas personas jóvenes, el significado de paz está asociado a la abolición de toda forma de violencia -especialmente las violencias simbólicas y estructurales como la exclusión, la pobreza y la discriminación-, pues consideran que de ellas se derivan las violencias físicas.

En tercer lugar, el significado de paz alude al cuidado de las nuevas generaciones $\mathrm{y}$ al aseguramiento de los derechos, y aparece como aspecto relevante en el significado de la paz entendida como una posibilidad ligada a la capacidad imaginativa, a su indeterminación y a la construcción permanente como proyecto de ser. Según los jóvenes y las jóvenes, la paz es un proyecto de existencia conjunta que se va forjando en un momento histórico, según lo que se valore como significativo y deseado. En ese sentido, significan paz como acción consciente, creadora, social y transformadora.

Esta interpretación es sugerente porque permite contrastar los significados de paz que los individuos jóvenes expresan, con lo que 
Muñoz (2008) considera categorialmente como paz imperfecta, que rompe con las concepciones anteriores en las que la paz aparece como algo perfecto, infalible, utópico, terminado, lejano y solo alcanzable en el otro mundo, en la gloria, en los cielos, en el no-tiempo de dios. Este contraste ayuda a reconocer las prácticas pacíficas donde ocurran y a planificar de forma alternativa los futuros conflictivos y siempre incompletos.

En esta forma, la paz es acción social construida, constitutiva y compleja, y da cuenta de la condición humana.

La paz participa de lo real, pero ella misma se superpone a lo real; participa del sujeto, pero determina al sujeto y es éste quien la aplica o la disfruta. Está reflejada en el lenguaje y es constituida por el lenguaje. Es una institución cultural, y las culturas la instituyen y la destituyen. De ahí la importancia de un análisis fenomenológico de la paz que indague en sus interacciones y mediaciones simbólicas (Muñoz, 2008, p. 8).

La paz no es un estado natural del ser humano, ni depende únicamente de la regulación externa que ejerce la sociedad a través de las religiones o de los Estados, sino también del tipo de interacciones culturales. Por ello, la gente joven afirma en sus relatos que la paz incluye múltiples actores y procesos, y requiere de distintas estrategias sociales, políticas y económicas para su construcción y sostenimiento en las interacciones cotidianas:

"La paz es la creación de condiciones de vida digna para todos y todas, que los derechos se puedan disfrutar realmente $y$ que a nadie lo maten por pensar diferente" (ab.31).

"La paz es un estilo de vida que incluye a uno mismo y todas las personas y lugares en los que uno vive" (cp.2).

\section{"Potencias" familiares para la construcción de paz}

El tercer hallazgo, y uno de los más interesantes de esta investigación, se refiere al reconocimiento que hacen los sujetos jóvenes

1216 de las potencias familiares que permiten actuar en el ámbito de las interacciones cotidianas a favor de la construcción de condiciones de paz:

"Encontré que la potencia de mi familia es el afecto" (ab.22).

"Cuando entendi que no solo tenemos problemas, sino que también podemos actuar y que de hecho lo hacemos, comprendi que uno tiene muchas potencialidades que a veces no ve" (ab.14).

Recuérdese que, para Aristóteles (1978$980 \mathrm{a})^{1}$, la potencia es un principio metafísico de aquello que es contrario a lo imposible ${ }^{2}$. Es decir, la potencia es posibilidad permanente (Alvira, 2007). Para estos individuos jóvenes, su capacidad transformadora es su potencia. Según sus narrativas, las familias tienen la posibilidad de iniciar nuevos proyectos, de actuar para alcanzar objetivos de trascendencia. Es este sentido, las potencias familiares son las capacidades que motivan a las familias a iniciar proyectos que les permitan ampliar sus condiciones de vida. Las potencias familiares se expresan en sentidos y en actos intencionados sobre sus propias vidas. Algunas potencias que identifiqué en esta investigación son:

Potencia narrativa. Se refiere a la capacidad de las familias de crearse mediante las narraciones de sí mismas. Esta potencia teje tres asuntos: la historia del contexto del cual heredan y aprenden sentidos y prácticas, normas y costumbres; la historia del grupo, que transcurre en las interacciones según sus necesidades y capacidades y a partir de la cual crean su micro cultura. En estos asuntos, las familias crean su identidad grupal, su historia familiar, y se vinculan a una comunidad de sentido más amplia; las biografías de cada uno de sus integrantes en las que se identifica la experiencia de la familia, y la de sus integrantes. Esta potencia aparece de forma recurrente en varios relatos:

1 Las citas de Aristóteles las hacemos de acuerdo con la publicación de Immanuel Bekker en 1831-1836 de la obra completa de Aristóteles. Se indica la página (980), luego la columna (a ó b), y luego el año de la traducción del griego del que se cita el texto.

2 Para Aristóteles, la potencia es la capacidad de los seres de transformarse, es decir, de ser afectados por los accidentes que son causa de la transformación de su sustancia. Es pasar de la potencia al acto mediante las causas (material, eficiente, formal y final). 
"No es que sea fácil hablar de la historia de la familia de uno, porque hay muchas cosas que uno no acepta, pero creo que en la historia de la familia uno puede ver lo importante que es para uno" (ab.30).

"Escribir sobre la vida propia es muy complicado, pero vale la pena porque uno termina viendo cosas que no había visto y al final eso ayuda no solo a valorar, sino a actuar de otra forma; también me gustó escribir de mi familia porque luego me di cuenta, cuando les preguntaba cosas a ellos, que aunque somos de la misma familia cada uno la ve diferente, la siente distinto" (ab.8).

Esta potencia narrativa resulta valiosa para la construcción de la paz, porque permite que las familias exploren formas de comprender su historia para encontrar posibilidades que no se habían visto, pues no hacían parte de sus narraciones sobre sus relaciones familiares. En este sentido, la potencia narrativa permite fortalecer su identidad como grupo -como ocurre con las familias que se narran como violentas-, y encontrar en sus relatos aspectos que contradicen las narraciones hegemónicas y movilizan nuevas comprensiones y acciones desde las cuales significan paz como una práctica posible para ellos:

"Pienso que mi familia tiene cosas buenas y malas. Antes veía solo las malas, me disgustaba mucho porque creía que no éramos muy violentos, pero después de escribir mis relatos encontré tantas cosas que me gustan y que siempre hemos hecho, por ejemplo, desde pequeños nos enseñaron a ser responsables y a trabajar todos por igual en la casa, no que porque somos hombres no hacemos nada, y pues, eso sí que ayuda a la paz" (ab.24).

Potencia comunicativa-interactiva. La comunicación familiar es un proceso mediador de la vida de la familia para construirse a sí misma. La comunicación familiar alude al proceso interactivo, simbólico, transaccional y permanente, en un contexto histórico, en el que el grupo construye significados para orientar su vida. La comunicación incluye mensajes verbales y no verbales, percepciones, sentimientos y cogniciones de los integrantes del grupo familiar y del contexto. La potencia comunicativa alude a la capacidad de las familias de crear significados para dar forma a sus relaciones, y para transformar sus conflictos. Esta potencia es clave para construir paz, porque hace de la familia un espacio vital para formar personas capaces de reconocer la violencia como una construcción social que puede ser transformada. Esto estimula a crear nuevas formas de relación, sustentadas en la comunicación como una práctica interactiva:

"Mi familia me ha enseñado a relacionarme con los demás. Es con mis papás y mis hermanos que he aprendido a ser una persona que se sabe comunicar y que respete a los demás. Yo entendi con este trabajo que en la vida familiar lo más importante es que tenemos la capacidad de comunicarnos y de allí parte todo para poder arreglar los problemas sin peleas, sin hacer daño" (cp.21).

\section{Prácticas familiares para la construcción de paz}

Según Abric (2001), las prácticas sociales se crean a partir de aspectos como las condiciones sociales, históricas y materiales en las que ellas se inscriben, a partir de los modos particulares para ubicarse y relacionarse en un contexto. En este sentido, puede decirse que la vida social y familiar está hecha de prácticas que dan forma, relación y sentido a las interacciones, y permiten usar los recursos -materiales y simbólicos- para actuar juntos en el mundo. Según las narraciones de estos individuos jóvenes, las prácticas familiares son posibles por las potencias de los grupos. Estas prácticas sociales reproducen y transforman el mundo social. Se refieren a la necesidad de trasmisión y estabilidad y a la posibilidad de emergencia, creación y cambio.

Las prácticas familiares pueden ser entendidas como las actividades que expresan su capacidad de actuar, mediante la cual los grupos se relacionan con el contexto y entre sí, para construir, proyectar y cambiar 
sus procesos de relación con mediaciones educativas, dialógicas y afectivas. Según Fried-Schnitman (2011), la práctica familiar que crea condiciones de paz deriva en un emprendimiento creativo en el que las innovaciones pueden construirse, reconociendo y valorando situaciones, capacidades, recursos, diferencias, oportunidades y posibilidades de acción hacia el cambio o el fortalecimiento de sus relaciones.

En los relatos identifiqué cinco prácticas familiares que son aportes a la construcción familiar, de condiciones de socialización y relación que contribuyen a la generación de paz como una forma de vida en la familia que busca el despliegue de la libertad y la realización de las personas, según sus capacidades y sus necesidades.

\section{Compartir en familia}

La práctica de compartir en familia se manifestó en todos los relatos; por tanto, no se puede asociar con una forma particular de familia. Esta práctica puede verse en los diálogos en la familia, en el afecto, en la concertación y en la recreación, como expresiones para socializar a sus integrantes:

"Los domingos acostumbramos a ir a la ciclovía; lo hacemos para distraernos un poco de todas las labores y para compartir más tiempo. Esta es una práctica que contribuye a la paz porque es un espacio en el que podemos desestresarnos y evitar problemas" (ab.8).

"El pasado domingo salí con mi familia al bosque popular en el prado, sacamos un espacio para la recreación; este momento permitió que nos reencontráramos nosotros mismos $y$ con las personas que queremos, y permitió fortalecer vínculos afectivos y compartir como amigos, aprender los unos de los otros y vivir en paz" (ab.5).

Según las narraciones, estas prácticas se van creando gracias a la potencia comunicativainteractiva de las familias, y pueden llegar a ser constantes y a propiciar planeaciones previas para destinar tiempos, lugares $\mathrm{y}$ recursos a favor de la construcción de un tipo de relaciones más democráticas. Para estas familias, compartir es importante para la interacción. La práctica de compartir permite sentirse en familia, acompañados, reconocidos, protegidos, queridos, relajados, y los narradores piensan que esta práctica es necesaria en sus relaciones familiares porque con ella evitan situaciones violentas en la familia y se consolidan los vínculos afectivos que estimulan la comunicación en la familia y que propician la paz en hombres y en mujeres.

\section{Distribuir los trabajos domésticos}

Esta práctica familiar apareció especialmente en las narrativas sobre experiencias de familias extensas. El significado atribuido a esta práctica está relacionado con las condiciones de justicia en la familia. Los individuos participantes decidieron construir relaciones equitativas en las que se reconoce la necesidad de que todos los integrantes de la familia participen en la vida doméstica. Se nota que hay un esfuerzo familiar por reconocer el valor del trabajo de cuidado en la familia. Esta práctica cotidiana es significativa como aporte para crear condiciones de paz en la familia, porque favorece un intercambio justo y solidario entre los integrantes y propicia relaciones democráticas en el grupo que tienden a equilibrar la distribución sexual del trabajo doméstico, lo que se muestra en los siguientes relatos:

"Tenemos distribuidas las tareas domésticas, de acuerdo al tiempo libre de cada uno, de tal manera que sean equilibradas. Creo que esto aporta a la construcción de paz, porque en nuestro hogar no adoptamos los roles de género que han sido impuestos socialmente; reconocemos el valor del trabajo doméstico y la importancia de aportar los dos en el hogar" (ab.10).

"Cada 15 días, los domingos, mi mamá reparte justamente las labores domésticas a todos los integrantes de la familia y lo hacemos de la siguiente forma, esta es una práctica que contribuye a la paz dado que es 
un espacio en el cual todos hacemos partícipe de las actividades de la casa" (ab.18).

\section{Dialogar en familia}

Esta práctica apareció en formas diferentes en todas las narrativas analizadas, de modo que no está asociada a una forma particular de familia. En las experiencias narradas sobre el diálogo en familia, se comprende que el diálogo incluye formas de comprenderse a sí mismo, a los otros y a lo otro, a partir de lo que Sánchez (citada por Patiño-López, 2017a), denomina códigos sociolingüísticos. Según las narraciones de los jóvenes, el diálogo es acción a través del lenguaje, es construcción de significados compartidos a partir de la experiencia, es coordinación de acciones en contextos particulares, es posibilidad permanente de creación.

El diálogo se diferencia de hablar porque aquél está mediado por la reflexión sobre la acción, mientras que el hablar se asume como un acto aprendido de oralidad. El diálogo, según estas personas jóvenes, es una forma de interacción que constituye la vida en común. En el diálogo las personas se reconocen a sí mismas y a los otros como semejantes y diferentes. En él, las familias discuten, argumentan, escuchan, preguntan, aconsejan, solucionan, regañan y construyen; por eso consideran que no hay formas únicas de construir diálogo, sino más bien diversas formas según los actores, los contextos, los contenidos, los tiempos y las necesidades.

También asumen que el diálogo es una práctica tensional mediada por relaciones de poder. Según los individuos participantes, todo diálogo familiar está precedido por una historia, orientado por unas concepciones, atravesado por emociones y necesidades, y se disputa en él la legitimidad y la vigencia de formas de ser y de enunciar, de organizar y decidir, usualmente expresadas en roles, jerarquías, valores, conocimientos y procedimientos. Por ello, el diálogo genera tensión, alteración, intercambio entre las partes; no es una práctica vacía de juicios, ni abstraída del contexto. Desde lo social, dialogar en familia es una práctica cargada de lo que hemos sido y de lo que somos personal y colectivamente:

"El lunes nos sentamos almorzar mi sobrino, mi madre y yo. Fue un espacio agradable porque hacía mucho no lo hacíamos. Se generó cierta forma de paz en este espacio de compartir, ya que me sentí tranquila, y hubo una equidad frente a la opinión de cada una pese a lo tenso" (ab.23).

"Cada que tenemos algún inconveniente o desacuerdo, problema, escuchamos los puntos de vista de cada uno, para así tomar decisiones conjuntas; con esta práctica aportamos a la construcción de paz porque aceptamos la diferencia de pensamiento, entendemos que mediante el diálogo podemos construir más como pareja", (ab. 10).

\section{Tomar decisiones de forma conjunta}

Esta práctica familiar apareció especialmente en las narraciones de los estudiantes y las estudiantes con familias extensas. El significado que le otorgan a esta práctica los sujetos participantes se relaciona con las condiciones de participación y de distribución del poder en la familia, mediante la reconfiguración de las asimetrías o jerarquías, según condiciones tales como el género y la generación.

En las narrativas se observa que para estos individuos jóvenes, la toma conjunta de decisiones permite que, sin importar el género o la generación, los integrantes de la familia tengan la posibilidad de ejercer el derecho de pensar y resolver asuntos que los incluyen, como la distribución de los ingresos, la priorización de necesidades, los castigos y los estímulos, los horarios de salida y entrada, entre otros. Además, la práctica familiar de tomar decisiones conjuntas se refiere a la construcción de formas de relación basadas en el respeto, en la confianza, en el reconocimiento y en la cooperación, a partir de lo cual se hace posible incentivar la autonomía y la corresponsabilidad en los asuntos del grupo. 
"Entre todos miramos qué hacer, cada quien opina y luego se toma la decisión más justa para todos. Para mí, esto aporta a la construcción de paz porque le da un lugar a cada quien en los asuntos importantes de la familia" (ab.21).

"Nos sentamos en la mesa, revisamos el problema y proponemos qué hacer. No es fácil, porque todos pensamos diferente. Esto construye paz porque es más justo y mejora las relaciones entre nosotros" (ab.28).

\section{Cuidar en Familia}

Esta práctica la observé en la mayoría de los relatos $\mathrm{y}$, por tanto, no se refiere a una sola forma de familia que la realiza. La práctica de cuidar en familia se refiere a las formas de garantizar el bienestar de sus integrantes. Esta práctica trasciende los trabajos de manutención física y satisfacción de necesidades biológicas. Los sujetos jóvenes consideran que el cuidar en familia es un trabajo relacional, para dar bienestar emocional y espiritual en las tristezas, los duelos y las enfermedades. Se relaciona con todas las tareas cotidianas que implican ayudar al desarrollo del otro; por tanto, es una práctica vinculada a la solidaridad con el otro, a su reconocimiento como alguien importante en el círculo afectivo relacional más amplio de cada persona y grupo familiar.

Desde las experiencias de estos sujetos jóvenes, cuidar en familia es una práctica que aporta a la construcción de paz, porque ayuda a democratizar las relaciones puesto que distribuye las responsabilidades entre todos los integrantes del grupo, más allá del sexo, el género y la generación, y facilita la consolidación de vínculos afectivos de reciprocidad y cercanía, sustentados en asuntos como la justicia. Cuidar deja de ser un asunto de mujeres, asociado a la naturaleza femenina; este verbo pasa a ser comprendido como una posibilidad resultante de un tipo particular de relaciones que se construyen a partir de procesos de socialización que no están centrados en las diferencias sexuales entre hombres y mujeres, sino más bien en el reconocimiento de una responsabilidad compartida que involucra a cada integrante de la familia.

"Mi abuelo Ovidio es un adulto mayor de 82 años, él tiene Parkinson $y$ por tal motivo se le dificulta el movimiento coordinado de sus pies, lo que ha causado varios accidentes con heridas en su cuerpo. Desde el primer día que se cayó, tomé la decisión de acompañarlo a todo tipo de citas médicas y me encargo de reclamar todos sus medicamentos" (ab.14).

"Mi hermano y yo nos hacemos mandados, si el uno necesita algo el otro sale y se lo trae, si alguno está realizando algún trabajo en la casa o está en la cama el otro le pasa lo que necesita" (ab.16).

Finalmente, los resultados de la investigación me permiten afirmar que en Colombia, para hacer factible la construcción de paz como proceso social, es necesario ampliar la mirada hacia las relaciones situadas en lo local, en lo cotidiano, en lo íntimo y en lo familiar; esas relaciones que denotan emergencias continuas y que hacen parte del nosotros, pero que usualmente no son consideradas como potenciales en las transformaciones democráticas.

\section{Conclusiones}

1. La construcción de la paz como una práctica social que se da a partir de las interacciones entre actores en distintos escenarios, requiere:

- Reconfigurar el concepto y la práctica de la democracia, lo que implica su ejercicio consciente en todos los ámbitos de la vida social, la participación de diversos actores, escenarios y procesos (Estado, academia, empresa privada, sociedad y familia).

- Ampliar nuestra comprensión y acción sobre la paz. Para ello es necesario asumirla como: a) una construcción social de acuerdos situados históricamente, por tanto, móvil y compleja; b) un derecho relacionado con la posibilidad de vivir libre, digna y tranquilamente una vida normal que no implique riesgo de muerte o daño por violencia, exclusión o 
desigualdad; c) un proceso social asociado con la democracia en todos los ámbitos de la vida humana, más allá de la relación EstadoCiudadano. Esto significa entender que la familia es un escenario de formación necesario en la construcción de paz.

- Entender que la paz se expresa en discursos y prácticas cotidianas que aprenden y enseñan, y se transforman en procesos de socialización como los que realiza la familia; por tanto, es necesario asumirla como parte de los aprendizajes y prácticas que los niños, niñas y jóvenes desarrollan en las interacciones con sus padres, madres, y demás familiares.

- Democratizar las relaciones íntimas, privadas y públicas, y no solo las que median entre el Estado y la sociedad. De ahí la importancia de reconocer a las familias como agentes centrales en los procesos de construcción de paz desde la vida cotidiana. La democracia familiar puede favorecer la formación de personas capaces de participar en la toma de decisiones sociales, porque toman conciencia de los mecanismos simbólicos y materiales que ocasiona la desigualdad social.

- Crear condiciones democráticas en la distribución del poder y de los trabajos, a fin de facilitar el acceso a recursos, propiciar el reconocimiento, ampliar los vínculos afectivos y favorecer el disfrute de espacios de creación, ocio y convivencia.

- Formar potenciales éticos, comunicativos, afectivos y creativos en las familias, mediante prácticas socializadoras que expresen formas de significar y hacer la paz. Esto es necesario porque históricamente se ha desdeñado la vida familiar como fuente de paz.

\section{Lista de referencias}

Abric, J. C. (2001). Las representaciones sociales: aspectos teóricos. En J. C. Abric (ed.) Prácticas sociales y representaciones (pp. 11-32). México, D. F.: Ediciones Coyoacán.

Alvarado, S. V.; Ospina, H. F.; Quintero, M.; Luna, M. T.; Ospina-Alvarado, M. C. \& Patiño-López, J. A. (2012). Las escuelas como territorios de paz. Construcción social del niño y la niña como sujetos políticos en contextos de conflicto armado. Buenos Aires: Clacso.

Alvira, T. (2007). Significado metafísico del acto y la potencia en la filosofía del ser. Navarra: Universidad de Navarra.

Aris-tóteles (1978-980a). Metafísica. México, D. F.: Porrúa.

Bouthoul, G. (1951). Les guerres. Éléments de polémologie. París: Payot.

Bruner, J. (1989). Acción, pensamiento y lenguaje. Madrid: Alianza.

Bruner, J. (2004). Realidad mental y mundos posibles: los actos de la imaginación que dan sentido a la experiencia. Barcelona: Gedisa.

Castoriadis, C.(2007). La institución imaginaria de la sociedad. Buenos Aires: Tusquets.

Centro Nacional de Memoria Histórica (2013). ¡BASTA YA! Colombia: memorias de guerra y dignidad. Bogotá, D. C.: Imprenta Nacional.

Creswell, J. W. (1998). Qualitative inquiry and research design: Choosing among five traditions. Thousand Oaks. San Francisco: Sage Publications, Inc.

Durán, A.; Medina, A.; González, N. \& Rolón, I. (2007). Relación entre la experiencia de la separación parental y la construcción de un proyecto de vida del joven y la joven universitarios. Universitas Psychologica. 6 (3), pp. 713-725.

Echeverría, R. (2003). Ontología del lenguaje. Santiago de Chile: Comunicaciones Noreste Ltda.

Fairclough, N. (2008). El análisis crítico del discurso y la mercantilización del discurso público: las universidades. Revista Discurso y Sociedad, 2 (1), pp. 170-185.

Foucault, M. (1980). Power/knowledge: Selected interviews and other writings. Nueva York: Pantheon Books.

Freeman, J.; Epston, D. \& Lobovits, D. (2001). Terapia narrativa con niños: aproximación a los conflictos familiares a través del juego. Barcelona: Paidós.

Fried-Schnitman, D. (2011). Afrontamiento generativo de crisis y conflictos en organizaciones. Persona (14), pp. 11-40.

Fried-Schnitman, D. (2015). Diálogos para la 
transformación: experiencias en terapia $y$ otras intervenciones psicosociales en Iberoamérica. Buenos Aires: Taos Institute Publications.

Gergen, K. (2007). Construccionismo social. Aportes para el debate y la práctica. Bogotá, D. C.: Uniandes.

Guattari, F. (1996), Subjectivities: For Better and for Worse, En G. Genosko (ed.) The Guattari Reader. Oxford: Blackwell.

Lechner, N. (1997). El malestar con la política y la reconstrucción de los mapas políticos. En R. Winocur (ed.) Culturas politicas a fin de siglo. México, D. F.: Flacso.

Maganto, C. \& Ibáñez, C. (2010). Utilidad clínica de la autobiografía. Revista de Psicoterapia, 21 (82-83), pp. 83-105.

Muñoz, F. (2008). La paz imperfecta ante un universo en conflicto. Recuperado de: http://wdb.ugr.es/ eirene/wp-content/files/ publicaciones/ColeccionEirene/eirene 15/ eirene15cap1.pdf

Páramo, P. (2008). La construcción psicosocial de la identidad y del SELF. Revista Latinoamericana de Psicología, 40 (3), pp. 539- 550 .

Patiño-López, J. A. (2012). Posibilidades de la investigación narrativa en los procesos de desarrollo familiar. Revista Latinoamericana de Estudios de Familia, 4, pp. 227-240.

Patiño-López, J. A. (2017a) Entrevista a la profesora María Hilda Sánchez. Revista Latinoamericana de Estudios de Familia, 15 (1), pp. 618-624.

Patiño-López, J.A. (2017) Narraciones y relatos autobiográficos sobre la construcción de la vida en familia. Manizales: "ojo con la gota de TiNta (una editorial pequeña e independiente)".

White, M. (1987). Famiy therapy and schizophrenia: Addressing the "In-thecorner lifestyle. Spring: Dulwich Centre Newsletter.

White, M. \& Epston, D. (1993). Medios narrativos para fines terapéuticos. Barcelona: Paidós. 